\title{
AUGMENTED REALITY PEMBELAJARAN PRAKARYA INTERAKTIF UNTUK MATERI KETERAMPILAN DARI LIMBAH SAMPAH ANORGANIK (STUDI KASUS DI SMP MARHAS MARGAHAYU)
}

\author{
Siti Sifa Maesaroh ${ }^{1}$, Harya Gusdevi $^{2}$, M. Reksa Ariansyah ${ }^{3}$ \\ Program Studi Teknik Informatika, Sekolah Tinggi Teknologi Bandung , 2,3 \\ sitisifa822@gmail.com¹, devi@sttbandung.ac.id ${ }^{2}$, reksa@sttbandung.ac.id ${ }^{3}$
}

\begin{abstract}
Abstrak
Teknologi augmented reality merupakan aplikasi penggabungan dunia nyata dengan dunia maya dalam bentuk dua dimensi maupun tiga dimensi yang diproyeksikan dalam sebuah lingkungan nyata dalam waktu yang bersamaan. Saat ini augmented reality dapat dijadikan sebagai media pembelajaran sehingga pembelajaran lebih menarik, interaktif dan menyenangkan, seperti halnya aplikasi yang dibangun ini yaitu aplikasi pembelajaran prakarya interaktif menggunakan augmented reality khususnya untuk materi keterampilan dari limbah sampah anorganik. Kesulitan muncul ketika dalam penyampaian materi seperti penyampaian langkahlangkah pembuatan kerajinan tersebut masih menggunakan buku dan pengalaman guru. Maka diperlukan sebuah aplikasi pembelajaran interaktif yang memanfaatkan teknologi augmented reality.
\end{abstract}

Kata Kunci: Aplikasi Pembelajaran, Augmented Reality, Sampah Anorganik

\begin{abstract}
Augmented reality technology is an application that combines the real world with the virtual world in two-dimensional or threedimensional forms that are projected in a real environment at the same time. Currently, augmented reality can be used as a learning medium so that learning is more interesting, interactive and fun, just like the application that was built, which is an interactive craft learning application using augmented reality, especially for skill material from inorganic waste. Appears when the delivery of material such as the delivery of the steps for making the craft still uses books and the teacher's experience. So we need an interactive learning application that utilizes augmented reality technology.
\end{abstract}

Keywords: Learning Application, Augmented Reality, Inorganic Waste

\section{PENDAHULUAN}

Media pembelajaran sangat diperlukan dalam menunjang proses Pendidikan. Perkembangan teknologi yang semakin baik, tentunya sangat berpengaruh diberbagai sektor kehidupan manusia. Menurut [1] interaktif berarti bersifat saling mempengaruhi. Artinya antara pengguna (user) dan media (program) ada hubungan timbal balik, user memberikan respon terhadap permintaan/tampilan media (program), kemudian dilanjutkan dengan penyajian informasi/konsep berikutnya yang disajikan oleh media (program) tersebut. Salah satu aplikasi yang di terapkan di android adalah teknologi augmented reality yang merupakan aplikasi penggabungan dunia nyata dengan dunia maya dalam bentuk dua dimensi maupun tiga dimensi yang diproyeksikan dalam sebuah lingkungan nyata dalam waktu yang bersamaan. Augmented reality adalah sebuah teknologi yang mengabungkan antara benda maya baik dua dimensi atau tiga dimensi kedunia nyata. Augmented reality berdasarkan deteksi citra dan citra yang digunakan adalah marker[4]. Dengan penggunaan teknologi augmented reality media pembelajaran akan lebih interaktif yang mana pembelajaran akan lebih menarik dan menyenangkan.

SMP MARHAS margahayu salah satu lembaga pendidikan menengah pertama swasta yang terletak di jalan Sayati Hilir No.51 / Cedok Margahayu Kabupaten Bandung. Salah satu mata pelajaran yang dipelajari yaitu prakarya dalam mata pelajaran tersebut salah satu materinya yaitu keterampilan yang dimana para siswa membuat sebuah kerajinan dari limbah sampah. Penggunaan bahan limbah sampah setiap kelas berbeda. Untuk kelas 7 bahan yang digunakan adalah limbah keras seperti bekas baju untuk tas, sedangkan untuk kelas 8 menggunakan bahan limbah sampah lunak seperti kertas dan untuk kelas 9 sendiri yaitu penggabungan dari kelas $7 \& 8$ atau media campuran. Selain bahan yang digunakan bapak Moch Bani Salsabil selaku guru Seni Budaya juga menyatakan bahwa dalam materi penyampaian langkah-langkah pembuatan kerajinan tersebut masih menggunakan buku dan pengalaman kemudian dijelaskan kepada siswa yang dimana menurut bapak Moch Bani Salsabil hal tersebut kurang efektif karena penyampaian kurang dipahami sehingga siswa kesulitan mengikuti langkah-langkah karena gambar masih berbentuk 2D sehingga hanya dapat dari satu sudut saja. Selain itu menurut bapak Moch Bani Salsabil dengan hanya penggunaan buku dan pengalaman saja materinya dirasa kurang lengkap.

Berdasarkan permasalahan yang telah dipaparkan, maka diperlukan sebuah aplikasi pembelajaran interaktif yang memanfaatkan teknologi augmented reality khususnya untuk Materi Keterampilan dari Limbah Sampah Anorganik. 


\section{TINJAUAN PUSTAKA}

1. Media Pembelajaran Interaktif

Menurut [1] interaktif berarti bersifat saling mempengaruhi. Artinya antara pengguna (user) dan media (program) ada hubungan timbal balik, user memberikan respon terhadap permintaan/tampilan media (program), kemudian dilanjutkan dengan penyajian informasi/konsep berikutnya yang disajikan oleh media (program) tersebut. Menurut [2] secara umum media pembelajaran adalah alat bantu dalam proses belajar mengajar. Sesuatu yang dapat dipergunakan untuk merangsang pikiran, perhatian, perasaan, dan kemampuan atau keterampilan pelajar tersebut sehingga dapat mendorong terjadinya proses belajar atau kegiatan pembelajaran. Batasan dari media pembelajaran ini cukup luas dan mendalam dengan mencakup pengertian sumber, manusia dan lingkungan serta metode yang dimanfaatkan dari tujuan pembelajaran. Sedangkan menurut [3], media pembelajaran merupakan segala sesuatu yang digunakan dalam kegiatan belajar mengajar agar dapat menstimulasi pikiran, perasaan, minat dan perhatian siswa sehingga terdapat sesuatu interaksi komunikasi edukasi antara guru dan siswa dalam proses belajar mengajar.

Berdasarkan penjelasan dari beberapa peneliti terdahulu yang telah dipapakan maka dapat disimpulkan bahwa media pembelajaran interaktif adalah sebuah media bantu dalam proses mengajar yang digunakan untuk merangsang pikiran, perasaan, minat dan perhatian para siswa sehingga terdapat interaksi timbal balik dari pengajar dan siswa.

\section{Augmented Reality}

Menurut [4] augmented reality adalah sebuah teknologi yang mengabungkan antara benda maya baik dua dimensi atau 3 dimenai kedunia nyata. Augmented reality berdasarkan deteksi citra dan citra yang digunakan adalah marker. [5] menyebutkan bahwa augmented reality pertama kali digunakan pada tahun 1957-1962 oleh seorang sinematografer bernama Norton Heilig, yang diberi nama Sensorama. Sensorama merupakan sebuah simulator yang dapat mensimulasikan visual, getaran, dan bau. [6] tujuan dari AR adalah mengambil dunia nyata sebagai dasar dengan mengabungkan beberapa teknologi virtual dan menambahkan data kontekstual agar pemahaman manusia sebagai penggunannya menjadi semakin jelas.

\section{Android}

Menurut [7] android adalah sebuah OS yang paling cepat berkembang dan terus berkembang pada satu waktu pembaharuan muncul hampir setiap buka bahkan sekarang mereka muncul sekitar sekali dalam enam bulan. Pada tahun 2008 versi android sederhana pertama di rilis. Pengembang Android memiliki prospek luar biasa jika memutuskan untuk mengembangkan pembelajaran lebih lanjut, akan menemukan bahwa permintaan untuk programmer android sangat besar dan karenanya sangat menguntungkan. Beberapa data menyarankan gaji lebih dari 100.000 dolar AS. Sedangkan menurut [8] android merupakan sistem operasi open source yang dimana semua orang bisa mengembangkannya hal itulah yang membuat perkembangan aplikasi android semakin cepat dan bertumbuh kembang. Beragam aplikasi mulai dari tool hingga permainan telah bertebaran dalam play store yang bisa anda unduh baik secara gratis maupun berbayar.

\section{Marker Augmented Reality}

Menurut [4] marker adalah sebuah pola yang dibuat dalam bentuk gambar yang di kenali oleh kamera. Menurut [2] salah satu metode augmented reality adalah menggunakan metode markerless augmented reality, dengan metode ini pengguna tidak perlu menggunakan sebuah marker (penanda) untuk menampilkan elemenelemen digital. Teknologi markerless augmented reality yang dikembangkan dalam perangkat android diharapkan dapat membuat implementasi augmented reality jauh lebih efisien, praktis, menarik, dan bisa digunakan dimanapun, kapanpun, oleh siapapun tanpa perlu mencetak marker.

\section{Vuforia}

Menurut [2] vuforia merupakan salah satu aplikasi yang dikembangkan untuk mendukung pembuatan augmented reality. Dibuat dalam bentuk SDK, vuforia memiliki kemampuan untuk melakukan pengenalan citra dalam perkembanagn image recognation. Terdapat dua jenis workflow dengan dasar database yang dapat dipilih oleh developer, yaitu Cloud Database dan Device Database.

\section{ANALISIS DAN PERANCANGAN}

1. Analisis Sistem

Analisis merupakan aktivitas yang dilakukan untuk mendefinisikan proses yang terjadi pada sistem saat ini untuk kemudian diusulkan sistem yang akan dibangun.

a. Analisis kebutuhan fungsional yang dibutuhkan untuk menentukan kebutuhan fungsional yang 
terdapat pada aplikasi pembelajaran interaktif ini yang dapat dilihat pada tabel I.

TABEL I

TABEL ANALISIS KEBUTUHAN FUNGSIONAL

\begin{tabular}{|c|c|c|c|c|}
\hline \multirow[t]{2}{*}{ User Story } & \multicolumn{4}{|l|}{ Functional Requirement \& Priorities } \\
\hline & High Priority & edium Priority & $\begin{array}{c}\text { Low } \\
\text { Priorit } \\
y\end{array}$ & $\begin{array}{l}\text { No } \\
\text { Priori } \\
\quad \text { ty }\end{array}$ \\
\hline $\begin{array}{l}\text { Penyampaian langkah-langkah } \\
\text { pembuatan kerajinan tersebut } \\
\text { masih menggunakan buku dan } \\
\text { pengalaman sehingga kurang } \\
\text { dipahami. }\end{array}$ & $\begin{array}{l}\text { Pemanfaatan } \\
\text { augmented reality untuk } \\
\text { penyampaian materi nya } \\
\text { sehingga lebih menarik dan } \\
\text { mudah di pahami oleh siswa. } \\
\text { Dengan cara penambahan fitur } \\
\text { scan gambar pada aplikasi. }\end{array}$ & \multirow[t]{2}{*}{$\begin{array}{l}\text { Fitur } \\
\text { petunjuk. } \\
\text { Fitur keluar. } \\
\text { Fitur kuis. } \\
\text { Fitur tentang. }\end{array}$} & & \\
\hline $\begin{array}{l}\text { Siswa kesulitan mengikuti } \\
\text { langkah-langkah dari dari buku } \\
\text { karena gambar masih berbentuk } \\
\text { 2D sehingga hanya dapat dari } \\
\text { satu sudut saja }\end{array}$ & $\begin{array}{l}\text { Pembuatan model 3D agar siswa } \\
\text { dapat melihat gambar langkah- } \\
\text { langkah dari beberapa sudut } \\
\text { menggunakan fitur scan. }\end{array}$ & & & \\
\hline
\end{tabular}

b. Analisis Kebutuhan Non Fungsional

Berikut ini adalah tabel kebutuhan non fungsional yang berfungsi untuk menentukan kebutuhan non fungsional pada pembuatan aplikasi pembelajaran interaktif pengolahan sampah yang dapat dilihat di tabel II.

TABEL II

ANALISIS KEBUTUHAN NON FUNGSIONAL

\begin{tabular}{|l|l|}
\hline \multicolumn{1}{|c|}{ Quality Attribute } & \multicolumn{1}{c|}{ Requirement Definition } \\
\hline Porttability & Aplikasi dapat digunakan dimana saja karena menggunakan android. \\
\hline User Friendly & Penggunaan fitur di aplikasi sangat mudah dipahami. \\
\hline Usability & $\begin{array}{l}\text { Tampilan aplikasi sederhana sehingga dapat mudah dipahami oleh } \\
\text { pengguna }\end{array}$ \\
\hline
\end{tabular}

2. Perancangan Sistem

a. Use Case Diagram

Use case diagram ini adalah gambaran tools-tools yang akan ada pada aplikasi pembelajaran interaktif prakarya khususnya pada materi keterampilan pembuatan kerajinan limbah sampah anorganik. Aplikasi ini terdiri dari satu actor yaitu pengguna dimana pengguna ini bisa guru ataupun siswa. Berikut ini gambaran use case diagram.

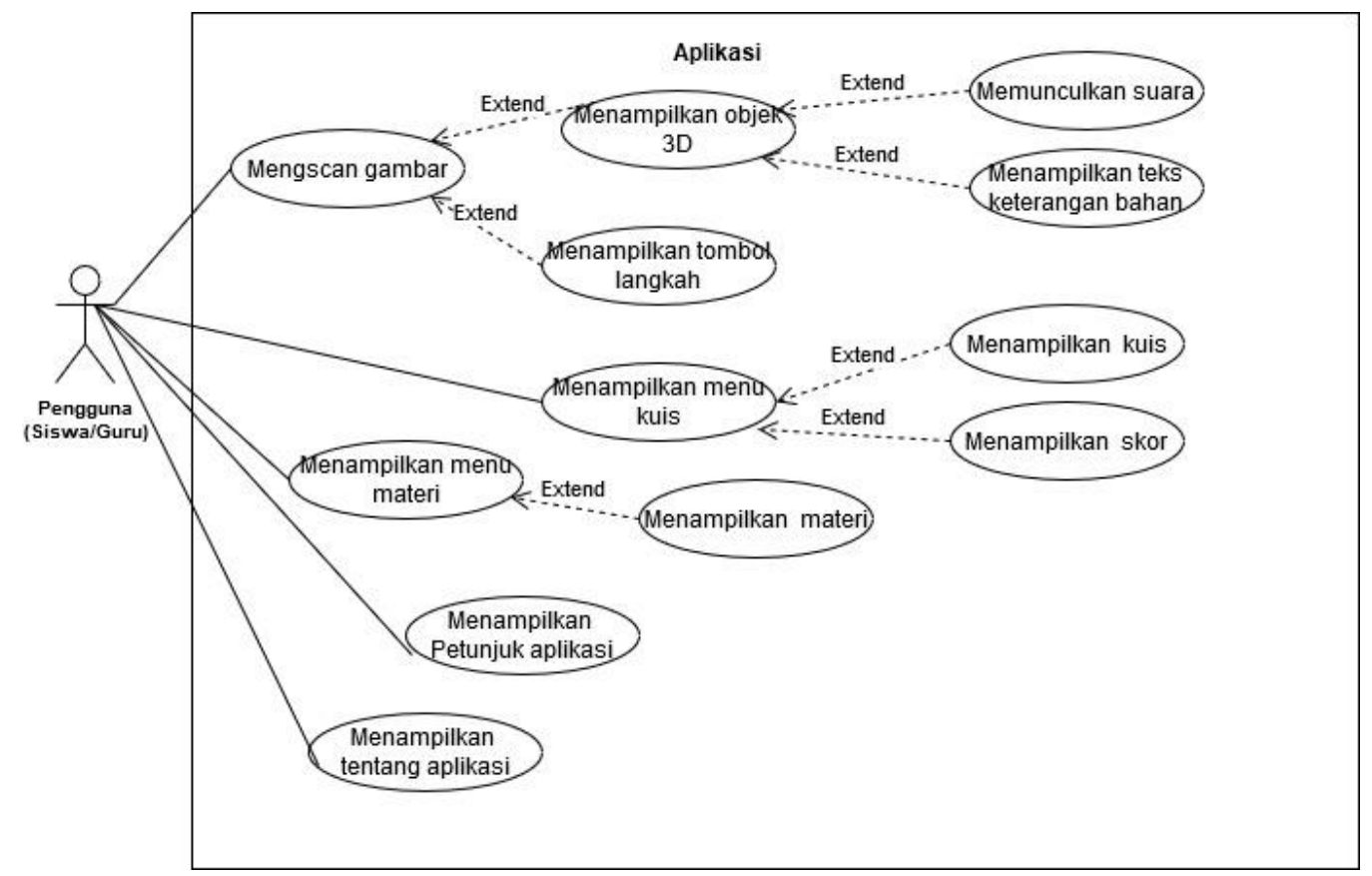

Gambar 1. Use Case Diagram Aplikasi Pembelajaran Prakarya Interaktif Prakarya Menggunakan Augmented Reality Khususnya Untuk Materi Keterampilan. 
3. Implementasi Sistem

a. Menu Utama

Menu utama ini sebagai halaman utama yang menampilkan menu-menu atau tombol-tombol yang dapat di akses oleh pengguna saat menggunkan apikasi pembelajaran seni dan keterampilan. Menu dalam apikasi pembelajaran seni dan keterampilan ini yaitu scan, kuis, materi, tentang, petunjuk dan keluar. Berikut ini adalah tampilan menu utama yang dapat dilihat di gambar 2 .

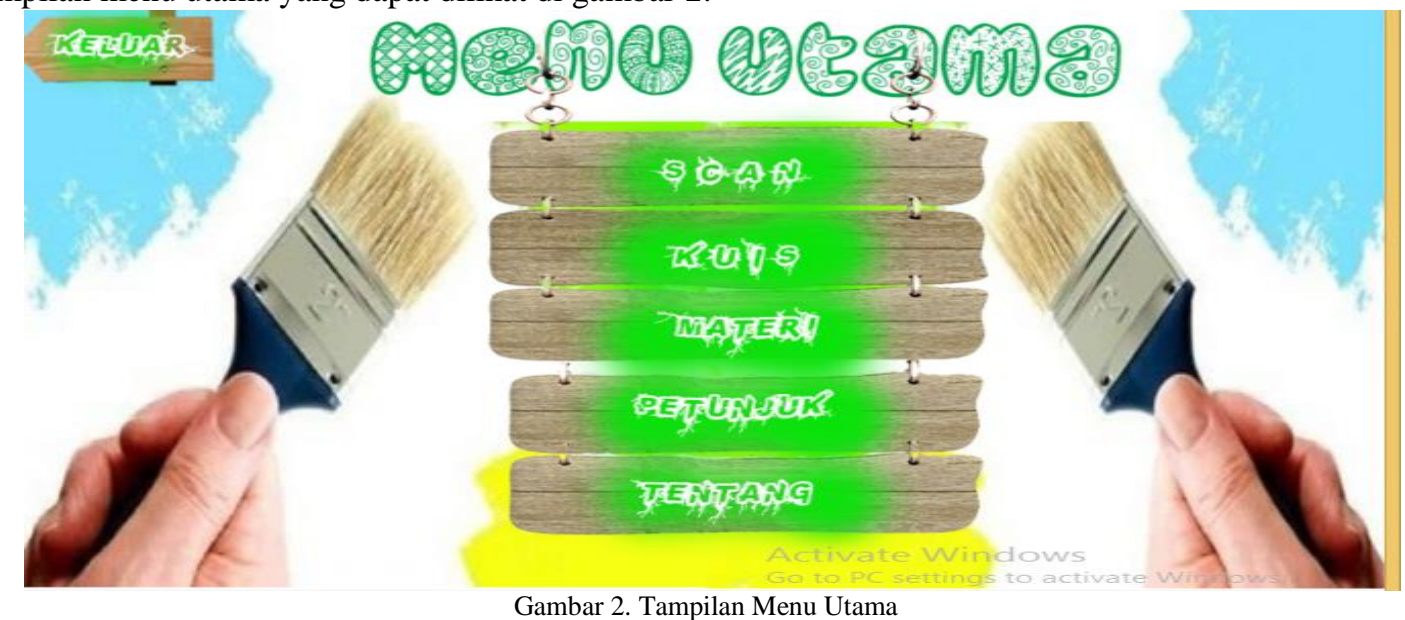

b. Tampilan Scan

Fitur Scan adalah fitur utama dalam Aplikasi Pembelajaran Seni Budaya Dan Keterampilan Interaktif Menggunakan Augmented Reality Khususnya untuk Materi Keterampilan dari Limbah Sampah ini.

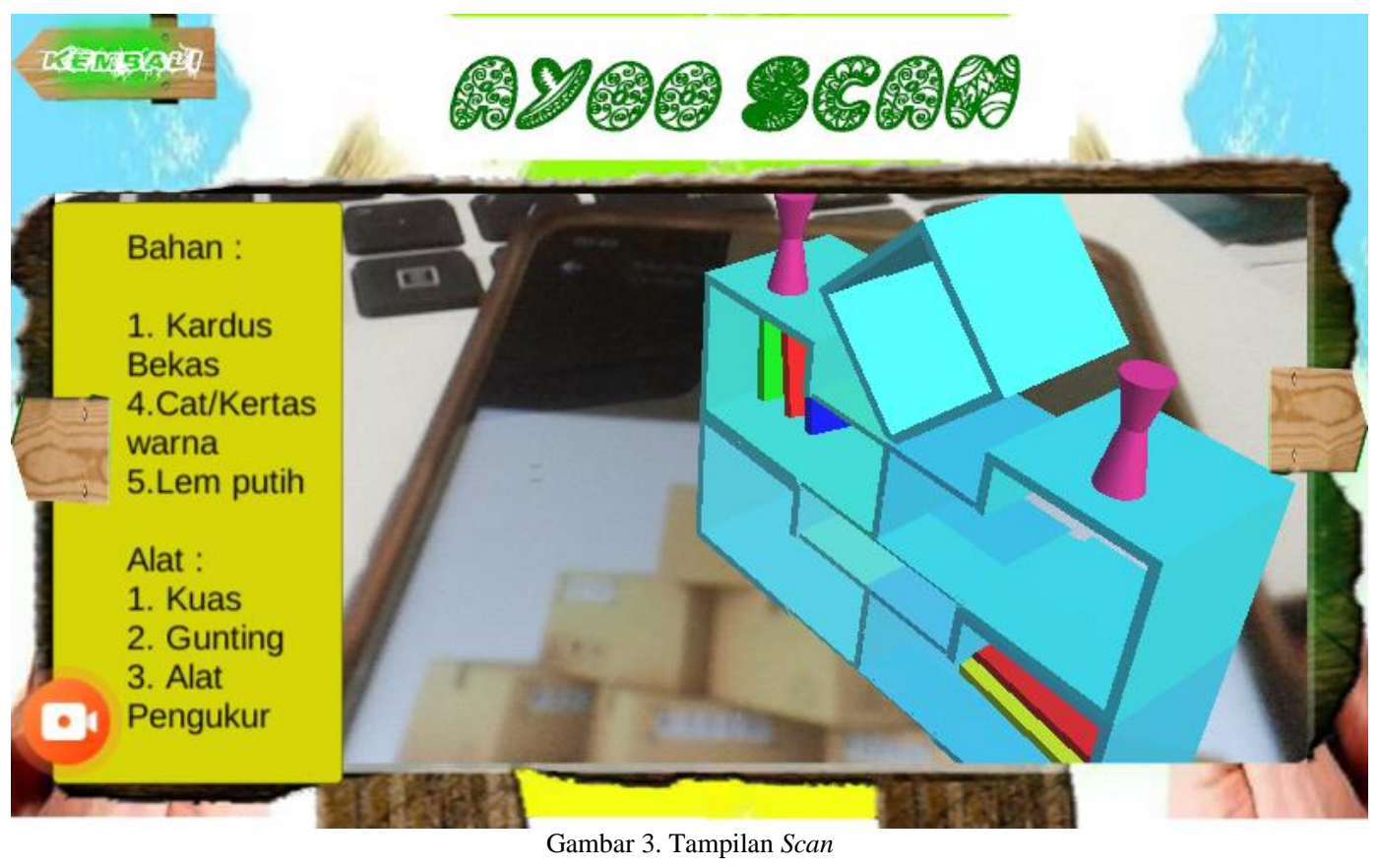


c. Tampilan Menu Kuis

Fitur menu kuis ini untuk mengukur pengetahuan para siswa/I SMP Marhas sesuai dengan kelasnya.

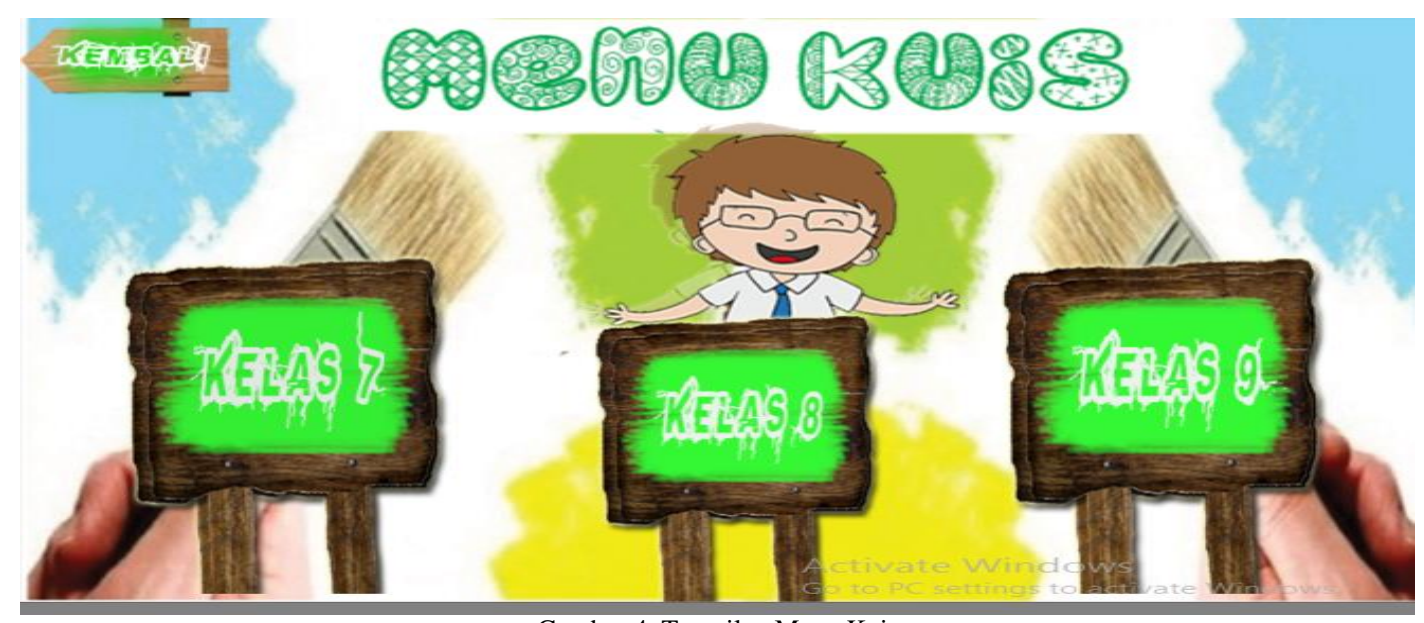

Gambar 4. Tampilan Menu Kuis

d. Tampilan Objek 3D dari Botol Lotion

Berikut ini adalah tabel gambar objek 3D dompet dari lotion.
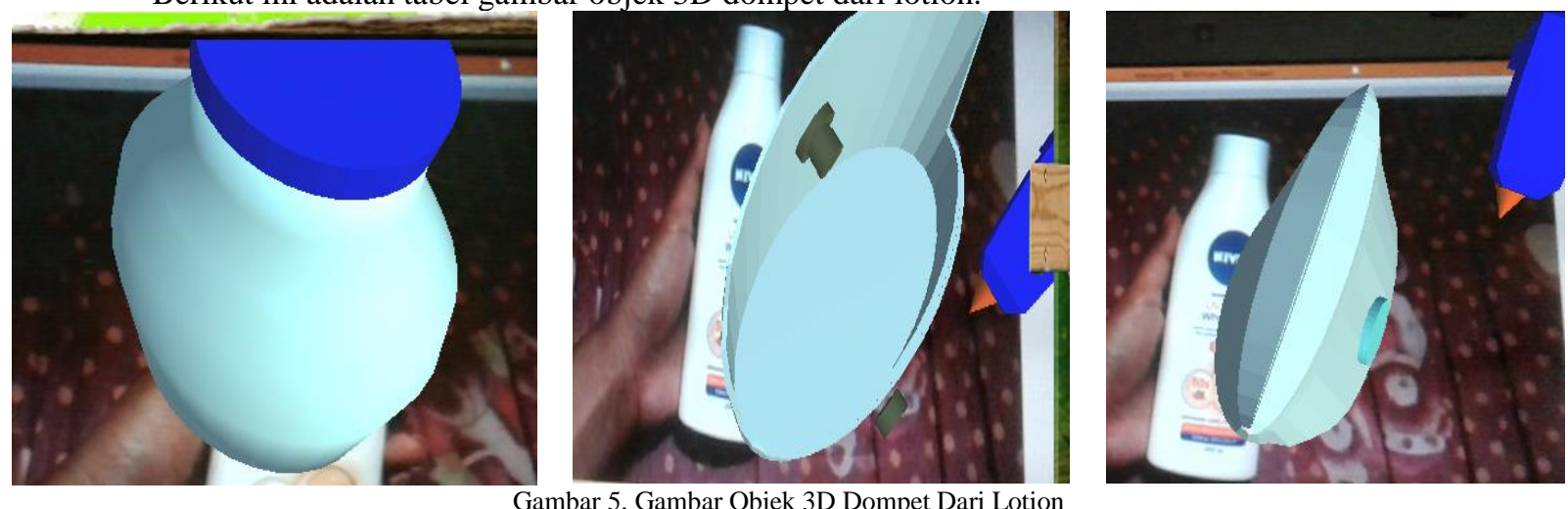

Gambar 5. Gambar Objek 3D Dompet Dari Lotion

e. Objek 3D Lemari dari Kardus

Berikut ini adalah tabel gambar objek 3D lemari dari kardus.

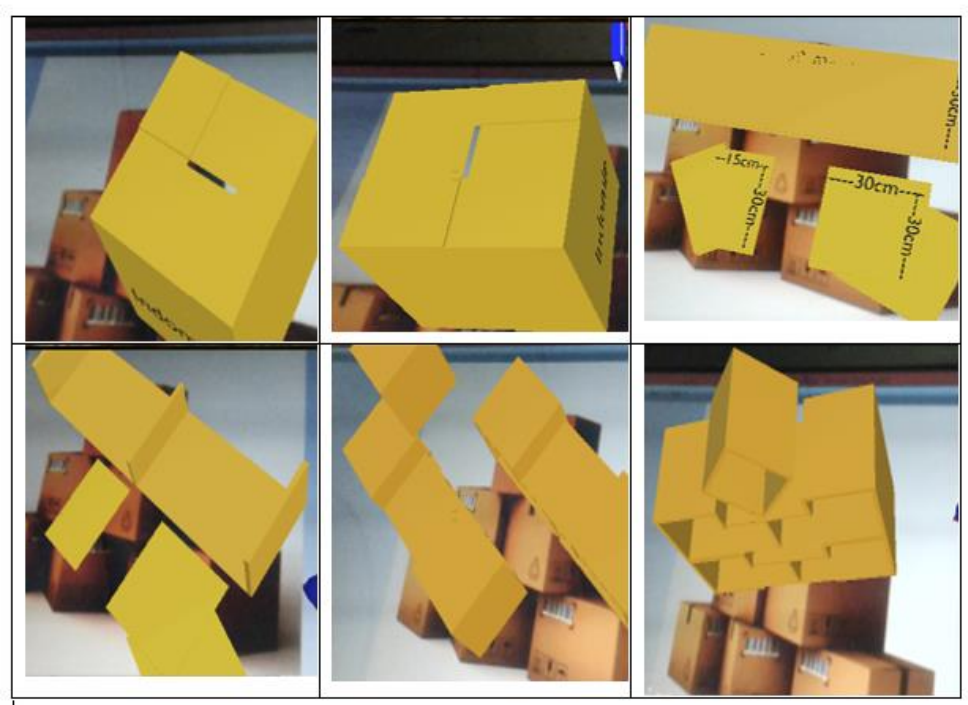

Gambar 6. Objek 3D Lemari dari Kardus 
f. Objek 3D Vas Bunga dari Aqua Gelas

Berikut ini adalah table gambar objek 3D vas bunga dari aqua gelas
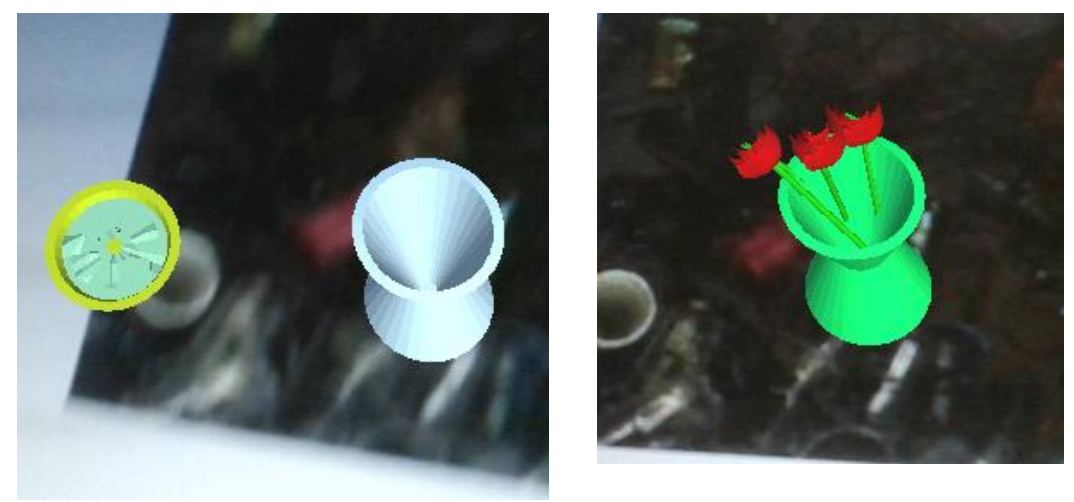

Gambar 7. Objek 3D Vas Bunga dari Aqua Gelas

\section{KESIMPULAN}

Berdasarkan hasil analisis dan pembahasan yang telah dilakukan, dapat disampaikan hal-hal sebagai berikut:

1. Aplikasi Pembelajaran Prakarya Interaktif merupakan aplikasi yang dapat membantu dan mempermudah guru dalam penyampaian materi karena menggunakan teknologi augmented reality sehingga penyampain materi lebih di pahami dan lebih menarik .

2. Aplikasi Pembelajaran Prakarya Interaktif merupakan aplikasi yang dapat mempermudah siswa dalam mengikuti langkah-langkah dengan membuat model 3D pada setiap langkahnya.

\section{REFERENSI}

[1] Fandhilah, F. (2016) 'Metode Pembelajaran Interaktif Kesenian dan Kebudayaan Indonesia pada Siswa Sekolah Dasar', Bina Insani ICT Journal, 3(1), p. 234321

[2] Saputro, R. E. and Saputra, D. I. S. (2015) Pengembangan Media Pembelajaran Mengenal Organ Pencernaan Manusia Menggunakan Teknologi Augmented Reality. Jurnal Buana Informatika, 6(2), pp. 153-162. doi: 10.24002/jbi.v6i2.404.

[3] Nofindra R (2019). Pengembangan Aplikasi Media Pembelajaran Interaktif Berbasis Android Pada Materii Pembelajaran 12 Prinsip Animasi.

[4] Wahid, A. A. and Mulany, H. F. (2019) Penerapan Augmented Reality Pada Aplikasi Pembelajaran', (July).

[5] N.R Raajan. et al. 2014. A Review on: Augmented Reality Technologies, System and Applications. Jurnal Asian Network for Scientific Information. 14(14). Hlm. 1485-1486.

[6] Kamelia L (2015). Perkembangan Teknologi Augmented Reality Sebagai Media Pembelajaran Interaktif Pada Mata Kuliah Kimia Dasar. Edisi Juni 2015 Volume IX No. 1 ISSN 1979-8911

[7] Neil Smyth (2017). Android Studio 3.0 Development Essential. Payload Media.

[8] M. Hilmi Masruri (2015). Buku Pintar Android. PT Elex Komputindo. Jakarta. Halaman 1. 